\title{
Megaprosthesis in distal femur nonunions in elderly patients-experience from twenty four cases
}

\author{
Raja Bhaskara Rajasekaran ${ }^{1}$ (D) - Dhanasekara Raja Palanisami ${ }^{1} \cdot$ Rajkumar Natesan $^{1}$ • \\ Dheenadhayalan Jayaramaraju ${ }^{1}$. Shanmuganathan Rajasekaran ${ }^{1}$
}

Received: 23 February 2019 / Accepted: 29 July 2019/Published online: 7 August 2019

(C) SICOT aisbl 2019

\begin{abstract}
Purpose of the study To evaluate the outcomes and complications using cemented megaprosthesis in elderly patients with distal femur nonunions (DFN).

Materials and methods Between 2012 and 2016, 24 patients of DFN with an average age of 71.8 years (66-83) and an average 1.9(1-3) prior surgery was managed with distal femur replacement using cemented modular endoprosthesis. Outcomes were analysed on the following criteria: implant status, complications, knee range of motion, Knee Society Score (KSS) and Musculoskeletal Tumor Society (MSTS) score.

Results All patients were extremely satisfied with their outcomes. At an average 22.1 months (10-43) follow-up, patients had an average $69.5^{\circ}\left(40^{\circ}-110^{\circ}\right)$ knee flexion, an average KSS of 75.7 (63-88) and an average MSTS score of 19.3 (17-25). Four patients died at an average 21.3 months after surgery due to causes unrelated to the fracture. One patient (4.1\%) had implantrelated complication; deep infection which required debridement and intravenous antibiotics. There were no late amputations or peri-operative deaths and no patient had aseptic loosening of components.

Conclusion By permitting immediate full weight-bearing ambulation and with most patients returning to an acceptable functional status, cemented megaprosthesis is a viable and useful single-stage management option in elderly patients with DFN.
\end{abstract}

Keywords Distal femur nonunions $\cdot$ Arthroplasty $\cdot$ Megaprosthesis $\cdot$ Elderly $\cdot$ Knee Society Score

\section{Introduction}

Distal femur nonunions (DFN) are a complex problem to the treating surgeon as they are inherently difficult to manage and also associated with significant patient disability [1-3]. This problem is compounded if it occurs in elderly patients as they are associated with a nonunion rate of $24 \%$ [4] due to factors like poor bone stock, low activity levels and medical comorbidities which lead to poorer outcomes $[5,6]$. Attempting re-fixation in these patients is associated with high chances of failure of fixation due to osteoporotic bone and metaphyseal bone loss [7, 8]. Moreover, adhering to protected weight-bearing following internal fixation is challenging to geriatric patients due to decreased cognitive status and muscle

Raja Bhaskara Rajasekaran

rajalibra299@gmail.com

1 Department of Orthopaedics \& Trauma, Ganga Medical Centre \& Hospitals Pvt. Ltd, 313, Mettupalayam Road, Coimbatore, India weakness which in turn may precipitate another failure of fixation [8]. Total joint replacement is a recognised management option in DFN as it avoids problems related to union and also avoids delayed weight-bearing. Cemented modular endoprosthetic replacement in managing DFN is a welldescribed option which enables immediate weight-bearing following surgery leading to faster recovery of geriatric patients [9-11]. Currently, the literature surrounding the use of endoprosthesis in DFN is limited to a handful of small case series with limited numbers of patients [6,10-12]. This study was performed to evaluate the outcomes and complications following cemented modular distal femoral endoprosthesis used in managing DFN in elderly patients.

\section{Materials and methods}

After obtaining approval from IRB (Institutional Review Board), we collected data retrospectively. All cases of DFN above the age of 65 years who were managed with cemented 
distal femoral replacement between 2012 and 2016 were included. Patients with infection, pathological fractures and periprosthetic fractures were excluded. Twenty-four patients formed the study group. The average age was 71.8 years (6683) with an average 1.9(1-3) number of prior surgeries. Medical records were reviewed to analyse the pre-injury status, subsequent treatments and co-morbidities.

The decision to perform a distal femoral replacement in these cases was made following a discussion by the treating surgeon with the patients as they were deemed likely to incur a poor outcome following another attempt at osteosynthesis. The assessment of osteoporosis and the degree of arthritis were made by the treating surgeon based on radiographs. No DEXA scans were used. All patients were evaluated with blood investigations, namely complete blood count, ESR and CRP, to rule out infection. Knee aspiration was done in all cases prior to surgery to rule out infection. All surgeries were performed by two experienced surgeons. The implants used in these cases were as follows: LPS - Limb Preservation System (DePuy Synthes, Warsaw, IN) was used in 18 patients (Fig. 1), Link Megasystem-C (Waldemar Link GmbH \& Co., Hamburg, Germany) in 3 patients (Fig. 2) and ResTOR Prosthesis (Sushrut-Adler Mediequip Pvt. Ltd., Devrukh, India) in 3 patients (Fig. 3). While the LPS system and the Link Megasystem-C were cemented moduar implants with a rotating hinge articulation, the ResTOR prosthesis was a cemented modular system with a fixed hinge articulation.

With regard to the surgical procedure, a standard midline incision was used. Using a medial parapatellar approach, the joint was exposed. The implants and the bone fragments of the nonunion were visualised. The distal femoral fracture fragments were resected and retained to allow for sizing of the components to aid in restoration of joint line. After taking an 8-mm proximal tibia cut, the tibial canal was reamed sequentially followed by assembling of final components. The tibial components were implanted with minimal cement beneath the tray. Following this, the femoral preparation was done. Using the removed femoral pieces of femoral bone, the measurement for the size of the components was planned. A trial placement of components was done to assess limb rotation and patellar tracking. The femoral canal was reamed and trial components were assembled. After placing a canal plug, the femoral canal was washed thoroughly with a pulse lavage and dried. Third-generation cementing technique using antibiotic-loaded cement was used in all cases. Wound was closed in layers with a suction drain. All patients received $150 \mathrm{mg}$ of oral Aspirin medication for 45 days as a routine for thromboprophylaxis following surgery.

In the post-operative period, CPM (continuous passive motion) exercises were started immediately on the same day of the surgery and all patients were allowed full weight-bearing walking from the first post-operative day onwards. Walker assistance was used in all patients during the first postoperative month to aid in mobilisation. Patients were discharged from the hospital following suture removal.

Radiographs were taken routinely at each follow-up. Radiographs were assessed for implant position and signs of loosening. Knee range of motion was assessed during each follow-up. Functional outcomes were assessed using Knee Society Score (KSS) and Muscuoskeletal Tumor Society (MSTS) score. The KSS is a functional scoring system scored on the basis of
Fig. 1 Distal femur nonunion with implant failure $(\mathbf{a}, \mathbf{b})$ following two previous attempts at fixation in a 72-year-old patient. Resected nonunion segment of the distal femur (c) with portion of the shaft resected (d) during surgery and manages with Depuy LPS Prosthesis (e). Follow-up radiographs (f, g) at 18 months post-surgery
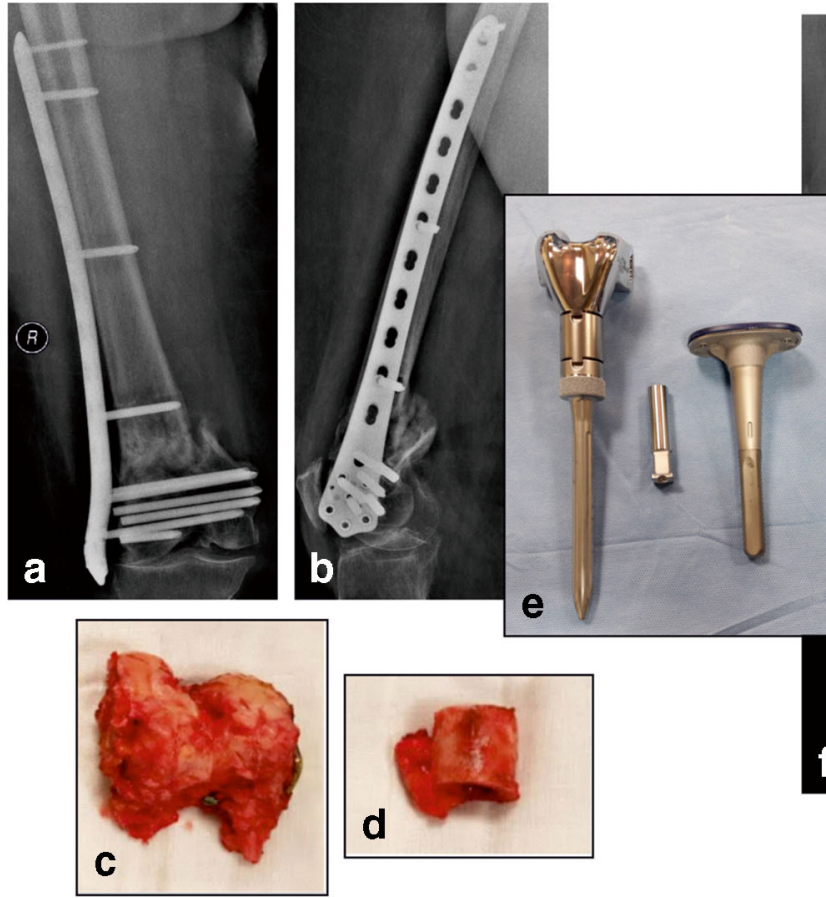
Fig. 2 Radiographs $(\mathbf{a}, \mathbf{b})$ of a 66year-old patient with nonunion of the distal femur with implant failure was managed with LINK Megasystem-C. Radiographs (c, d) at 24 months follow-up showing a well-functioning prosthesis
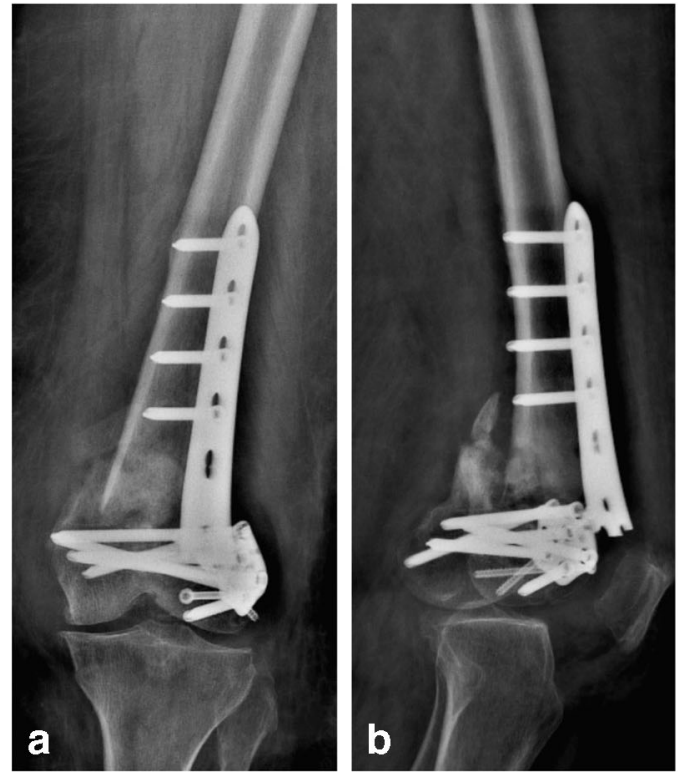

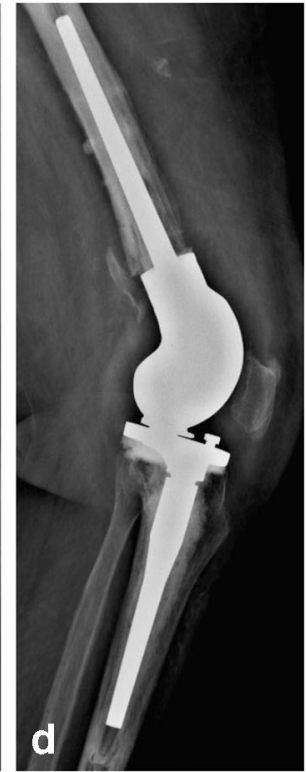

pain, range of motion, stability, alignment and function with a maximum of 100 points. The MSTS score is based on six categories namely pain, function, emotional acceptance, walking ability, support and gait with a maximum of 30 points.

\section{Results}

Twenty-four patients with an average age of 71.8 years (66-83) met the inclusion criteria and formed the study group. Patients had an average 1.9 (1-3) number of prior operations. Eleven patients (45.8\%) were ASA class III and 13 patients (54.1\%) were ASA class II. The average length of stay was ten days (817) and the average intra-operative blood loss was $400 \mathrm{ml}(300-$
$550 \mathrm{ml}$ ) with an average tourniquet time of 110 minutes (95125). At an average follow-up of 22.1 months (10-43), the average knee range of motion in all patients was $69.5^{\circ}\left(40^{\circ}-110^{\circ}\right)$. Four patients died at an average 21.3 months after surgery due to causes unrelated to the fracture. In all the surviving patients, the prosthesis showed no signs of loosening and was well functioning. The details of all patients and their outcomes are shown in Table 1.

\section{Complications}

In our series, out of the 24 patients, complications occurred in seven patients $(29.1 \%)$. Implant-related
Fig. 3 Nonunion with implant failure coupled with severe arthritis $(\mathbf{a}, \mathbf{b})$ in an 80-year-old patient was managed with ResTOR prosthesis. Radiographs (c, d) at 19 months post-surgery
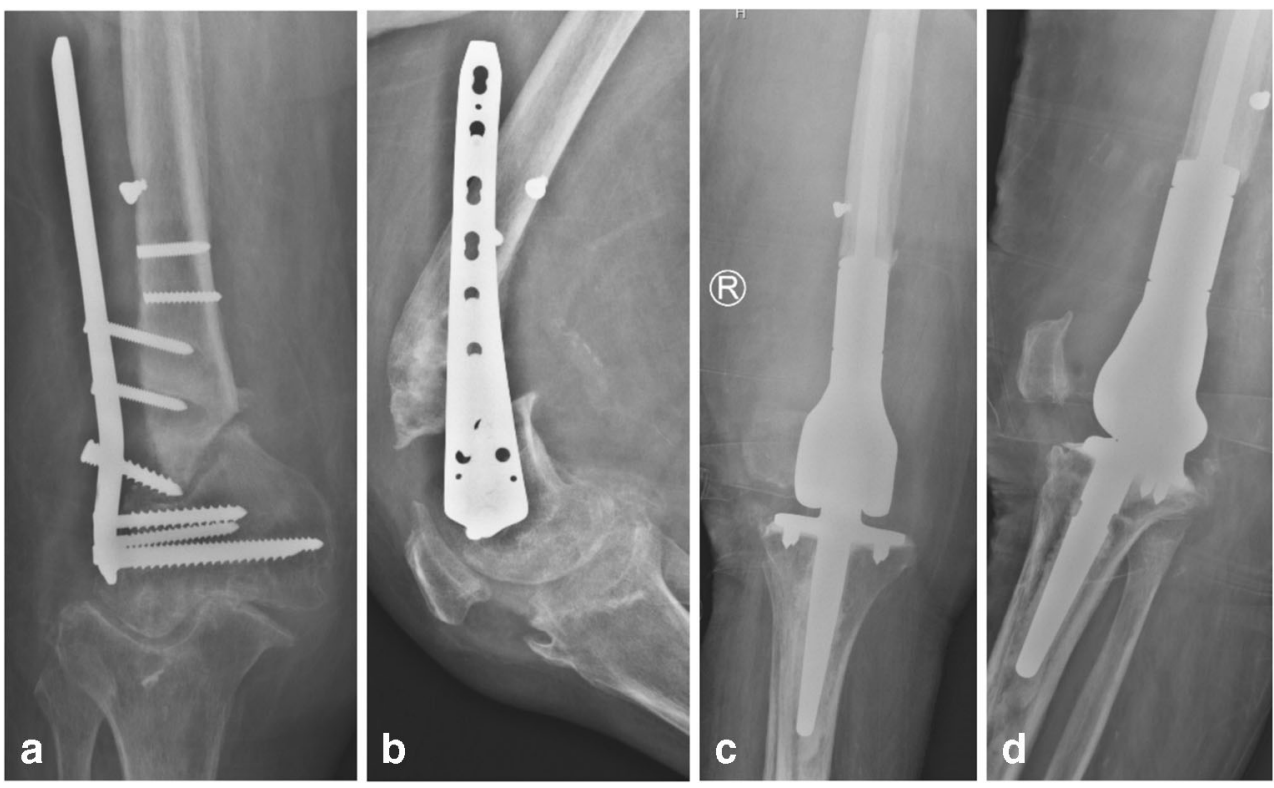
Table 1 Patient details with list of Implants used, post-op knee range of motion and ambulatory status following surgery and functional outcomes

\begin{tabular}{|c|c|c|c|c|c|c|c|c|c|c|c|}
\hline Patient & Age & Sex & $\begin{array}{l}\text { No. of prior } \\
\text { operations }\end{array}$ & $\begin{array}{l}\text { ASA } \\
\text { grade }\end{array}$ & Implant used & $\begin{array}{l}\text { Time to death } \\
\text { (months) }\end{array}$ & $\begin{array}{l}\text { Follow-up } \\
\text { (months) }\end{array}$ & $\begin{array}{l}\text { Post-op Knee } \\
\text { ROM (in degree) }\end{array}$ & $\begin{array}{l}\text { Assistance } \\
\text { while walking } \\
\text { (post-surgery) }\end{array}$ & KSS & $\begin{array}{l}\text { MSTS } \\
\text { score }\end{array}$ \\
\hline $\mathrm{A}$ & 67 & M & 2 & II & Depuy LPS & N/A & 18 & 80 & Cane & 77 & 21 \\
\hline B & 73 & M & 1 & II & Depuy LPS & N/A & 43 & 70 & None & 69 & 20 \\
\hline $\mathrm{C}$ & 69 & $\mathrm{~F}$ & 3 & III & Depuy LPS & N/A & 26 & 45 & None & 68 & 18 \\
\hline $\mathrm{D}$ & 72 & M & 2 & II & Depuy LPS & N/A & 18 & 90 & None & 82 & 23 \\
\hline $\mathrm{E}$ & 83 & $\mathrm{~F}$ & 3 & III & Depuy LPS & 24.5 & 18 & 70 & None & 75 & 22 \\
\hline $\mathrm{F}$ & 73 & M & 2 & II & ResTOR & N/A & 18 & 60 & Cane & 72 & 17 \\
\hline G & 74 & $\mathrm{~F}$ & 2 & II & Depuy LPS & N/A & 20 & 65 & None & 74 & 19 \\
\hline $\mathrm{H}$ & 69 & M & 1 & II & Depuy LPS & $\mathrm{N} / \mathrm{A}$ & 18 & 50 & Cane & 70 & 18 \\
\hline I & 68 & M & 2 & III & Depuy LPS & N/A & 24 & 100 & None & 86 & 21 \\
\hline $\mathrm{J}$ & 83 & M & 2 & III & Depuy LPS & N/A & 14 & 70 & None & 78 & 18 \\
\hline $\mathrm{K}$ & 81 & M & 1 & III & Depuy LPS & N/A & 24 & 110 & None & 85 & 18 \\
\hline $\mathrm{L}$ & 70 & M & 2 & III & Depuy LPS & N/A & 18 & 90 & None & 82 & 17 \\
\hline M & 71 & M & 1 & II & Depuy LPS & N/A & 22 & 65 & None & 82 & 19 \\
\hline $\mathrm{N}$ & 69 & $\mathrm{~F}$ & 2 & III & RestOR & 14.8 & 10 & 50 & None & 72 & 17 \\
\hline $\mathrm{O}$ & 68 & M & 3 & II & Depuy LPS & $\mathrm{N} / \mathrm{A}$ & 18 & 65 & None & 76 & 20 \\
\hline $\mathrm{P}$ & 76 & M & 2 & III & Depuy LPS & N/A & 24 & 60 & None & 71 & 19 \\
\hline Q & 67 & M & 3 & II & LINK Megasystem & $\mathrm{N} / \mathrm{A}$ & 35 & 40 & None & 72 & 18 \\
\hline $\mathrm{R}$ & 66 & M & 1 & III & Depuy LPS & $\mathrm{N} / \mathrm{A}$ & 32 & 105 & None & 88 & 25 \\
\hline $\mathrm{S}$ & 72 & $\mathrm{~F}$ & 2 & III & Depuy LPS & 33.4 & 28 & 55 & Cane & 72 & 22 \\
\hline $\mathrm{T}$ & 80 & $\mathrm{~F}$ & 2 & II & ResTOR & N/A & 19 & 40 & None & 63 & 18 \\
\hline $\mathrm{U}$ & 69 & M & 2 & III & Depuy LPS & N/A & 32 & 70 & Cane & 81 & 21 \\
\hline $\mathrm{V}$ & 70 & M & 2 & II & LINK Megasystem & 12.8 & 10 & 65 & Cane & 73 & 19 \\
\hline W & 66 & $\mathrm{~F}$ & 1 & II & LINK Megasystem & N/A & 24 & 75 & None & 74 & 18 \\
\hline$X$ & 68 & M & 2 & II & Depuy LPS & N/A & 18 & 80 & None & 76 & 17 \\
\hline
\end{tabular}

ASA, American Society of Anaesthesiologists; KSS, Knee Society Score; MSTS, Musculoskeletal Tumor Society

complication was seen only in one patient $(4.1 \%$, patient T) who had deep infection which required debridement, thorough irrigation and intravenous antibiotics. No patients had aseptic loosening of components or patellar maltracking. The complications are listed in Table 2.
Patient $\mathrm{C}$ was a 69-year-old lady who had diabetes, hypertension and heart disease with an ejection fraction of $55 \%$. During surgery, she developed BCIS (bone cement implantation syndrome). Immediately, the oxygen supplementation was increased, and aggressive resuscitation with intravenous

Table 2 List of complications, the interventions to manage them and the final outcome

\begin{tabular}{|c|c|c|c|c|}
\hline S.No & Patient & Complication & Intervention & Outcome \\
\hline 1 & $\mathrm{C}$ & BCIS & $\begin{array}{l}\text { Aggressive resuscitation and post-operative } \\
\text { ventilation }\end{array}$ & Recovered to normal \\
\hline 2 & $\mathrm{E}$ & Stage 2 decubitus ulcer & Wound care and air mattress & Ulcer healed completely \\
\hline 3 & $\mathrm{H}$ & DVT & Enoxaparin sodium injection therapy for 6 weeks & Complete resolution of thrombus \\
\hline 4 & $\mathrm{~K}$ & Hypotension, Electrolyte imbalance & $\begin{array}{l}\text { Volume replacement, intravenous therapy and } \\
\text { intensive care management }\end{array}$ & Recovered to normal \\
\hline 5 & Q & Superficial stitch abscess & Drainage of abscess and Oral antibiotics & Wound healed and no recurrence of infection \\
\hline 6 & $\mathrm{~T}$ & Deep Infection & Arthrotomy and DAIR & Wound healed and no recurrence of infection \\
\hline 7 & $\mathrm{X}$ & BCIS & Aggressive resuscitation and post-operative ventilation & Recovered to normal \\
\hline
\end{tabular}

$B C I S$, bone cement implantation syndrome; $D V T$, deep vein thrombosis; DAIR, debridement, antibiotics and implant retention 
fluid was done combined with vasopressor supplementation. Her blood pressure and saturation gradually picked up and oxygen supplementation was continued post-operatively. She required noninvasive ventilation for two days in the intensive care unit following which she returned to the ward to have an uneventful outcome thereafter.

Patient E was an 83-year-old lady who was obese and also had diabetes. Post-surgery, a 3-cm decubitus ulcer developed on the left gluteal region. She was managed with wound care, Neosporin powder and she was provided with an air mattress and the ulcer healed subsequently. The patient was doing well until her death due to renal failure two years after surgery.

Patient $\mathrm{H}$, a 69-year-old male, presented with pain and calf swelling of the right leg six weeks following surgery. On examination, he had tenderness over the calf and also had pain while dorsiflexing the foot. Venous Doppler revealed nonocclusive thrombus in the right posterior tibial and peroneal veins. He was managed with subcutaneous enoxaparin sodium injections for six weeks. Repeat Doppler scan revealed a resolution of the thrombus and at 18 months follow-up the patient was doing well.

Patient K, an 81-year-old male, who was a known case of diabetes, hypertension and had an ejection fraction of $50 \%$ became hypotensive on the evening of the surgery. He was transferred to the high dependency unit and observed there. He was managed with volume replacement to which the hypotension responded well. On the second post-operative day, he developed fatigue and appeared disoriented. His sodium level was $122 \mathrm{mEq} / \mathrm{L}$ and he was managed with intravenous therapy. His mobilisation was withheld for a couple of days until his sodium levels returned to normal. Following six days of treatment in the high dependency unit, he returned to the ward and he had no further complications.

Patient Q, a 67-year-old male, who was a diabetic presented six months following surgery with a stitch abscess over the anterior aspect of the knee. Under sterile precautions, the abscess was opened and the cultures grew gram-positive cocci. An aspiration of the knee joint was done which revealed no growth. Sensitive oral antibiotics were started to which the skin wound healed completely. At 35 months follow-up, the patient is doing well and there has been no recurrence of infection or wound problems.

Patient T, an 80-year-old lady, who was a diabetic presented six weeks following surgery with redness, increasing knee pain associated with movements. Her ESR, CRP and total leucocyte count were elevated. Knee aspiration revealed straw-coloured fluid which grew Staphylococcus aureus in culture. An arthrotomy was done and the knee was thoroughly debrided. Her components were retained. She received intravenous antibiotics for six weeks. Following which, her infection settled and her blood parameters returned to normal. She had no recurrence of infection, and at her last follow-up at months post-surgery, she was doing well.
Patient X, a 68-year-old male, who was a hypertensive and had an ejection fraction of $60 \%$, developed intraoperative dyspnoea and disorientation as soon as the tourniquet was released following cementing. He developed BCIS. He was immediately resuscitated and managed with fluids and vasopressors. He required intubation and post-operative ventilation for three days following which his lung parameters improved and he was weaned off the ventilator. He went on to have an uneventful outcome thereafter.

\section{Functional outcomes}

Functional outcome scores were calculated for all patients by the Knee Society Score (KSS) and Musculoskeletal Tumor Society (MSTS) score (Table 1). These scores were available for all 24 patients at an average of 20.6 months (12-43) postsurgery. Patients scored an average KSS of 75.7 (63-88) and an average MSTS score of 19.3 (17-25). All patients reported being extremely satisfied with their outcomes at their latest follow-up. Four of the 24 patients died an average 21.3 months (12.8-33.4) following surgery. All surviving patients had a well-functioning prosthesis at the time of their latest followup. Six patients (25\%) needed a cane to assist during ambulation whereas 18 patients $(75 \%)$ were able to ambulate independently at the time of their latest follow-up.

\section{Discussion}

Our study shows favourable results with megaprosthesis in managing DFN in elderly patients. To our knowledge, this is the largest study of endoprosthesis replacement for DFN in elderly patients. All our patients were allowed full weightbearing immediately post-surgery. Seventy-five percent of the patients were able to ambulate independently in the latest follow-up and all patients were extremely satisfied with their outcomes. We had a complication rate of $29.1 \%$ (7 patients) and had implant-related complication only in one patient $(4.7 \%)$. At the time of this report, all surviving patients had well-functioning prosthesis. Four patients died at an average 21.3 months following surgery due to factors not related with the fracture or surgery.

DFN which occur in elderly patients pose a challenge to the treating surgeon due to problems related to the fracture-like osteoporosis, metaphyseal bone loss and problems related to the patient like age, associated co-morbidities and decreased compliance $[1-4,13,14]$. With every nonunion in the distal femur, there is also associated implant toggling leading to inadequate bone stock making it difficult to achieve a good fixation during revision surgery. This problem is further compounded in elderly patients with osteoporosis $[6,7]$. Moreover, attempting another fixation surgery would involve 
restricted weight-bearing for about three months which would be very difficult for elderly patients to comply. Restricted weight-bearing in elderly patients would precipitate other medical problems due to prolonged immobilisation $[15,16]$. Hence, attempting another revision fixation would be associated with a higher chance of failure and higher incidence of complications. Use of a cemented megaprosthesis serves as an answer addressing all the above problems. Employing modular tumour prosthesis in distal femur fractures and nonunions have been described before. Bettin et al. [15] in their study of 18 acute distal femur fractures above 60 years managed with endoprosthesis reported good outcomes in all surviving patients. They suggested endoprosthesis replacements in acute distal femur fractures in elderly patients as a viable option as it provided immediate weight-bearing. Similar favourable results were seen in studies by Lundh et al. [17] in their study of 17 comminuted fractures around the knees in elderly. However, these studies involved acute distal femur fractures. Dealing with a nonunion of the distal femur is a completely different entity due to factors like fibrosis, knee stiffness and difficulty in exposure. These issues were echoed by Vaishya et al. [6] in their study of 10 cases of resistant DFN managed with megaprosthesis. While using megaprosthesis in DFN, two issues are of utmost importance in achieving a favourable outcome. Rotational alignment of the prosthesis is important to prevent gait abnormalities and restoration of the joint line is vital to prevent complications with regard to patellar maltracking and knee pain. Pre-operative planning with adequate radiographs and detailed examination is of utmost importance in these cases as most of the normal landmarks may be distorted due to the fracture and previous surgery.

Our results show that at the time of last follow-up, all patients had well-functioning prosthesis. Bettin et al. [15] in their study of 18 cases involving Depuy LPS Prosthesis showed all prosthesis to be well functioning at an average follow-up of 2.2 years. Vaishya et al. [6] who had employed MRS (Stryker, Howmedica) showed no implant complications like breakage or loosening at a median follow-up of four years. Berend and Lombardi [10] described 39 distal femur replacements in nontumour conditions to have an $87 \%$ implant survivorship at 46 month follow-up. Rosen and Strauss [12] reported a 71\% return to pre-operative ambulation levels and no revisions in their short follow-up of 11 months in 24 distal femur endoprosthesis. These results re-iterate that endoprosthesis is a useful single-stage solution within elderly patients resulting in favourable outcomes (Table 3).

Patients in our study achieved a decreased knee range of motion following surgery. An average knee flexion of 69.5 (40-110) was seen and this was mainly attributable to the scarring and fibrosis of tissues due to previous surgery. Eighteen patients $(75 \%)$ had more than one operation prior to the procedure, and during surgery, extensive soft tissue scarring and fibrosis was seen. Another reason would be that we used a medial parapatellar approach to perform this surgery in all our cases. Most of the cases had prior surgeries done through a lateral approach. Hence, the presence of two scars increased the scar tissue and thereby resulted in decreased range of motion. Hence, it would be necessary to counsel patients that complete range of motion prior to the initial injury would be difficult to achieve in these nonunions. However, all our patients were able to do all their daily activities without much assistance. It is also important to note that in elderly patients, physical demands are low and even a decreased degree of knee flexion would be acceptable.

Our complication rate $(29.1 \%)$ and functional outcomes were similar to other studies where endoprosthesis has been used in geriatric population. Bettin et al. [15] reported a $39 \%$ complication rate in their series of patients with an implantrelated complication of $11 \%$. Similar complication rates were seen in similar studies involving distal femur endoprosthesis replacement. In our study, two cases (8.3\%) developed bone cement implantation syndrome. This life-threatening complication is common in cemented arthroplasty in elderly patients. A study of 55 patients undergoing cemented hip arthroplasty
Table 3 Comparison of functional outcomes with similar studies involving megaprosthesis for distal femur fractures

\begin{tabular}{|c|c|c|c|c|}
\hline S.No & Study & No. of cases & $\begin{array}{l}\text { Average follow-up } \\
\text { (in months) }\end{array}$ & Post-operative functional outcome \\
\hline 1 & Bettin et al. [15] & 18 & 27.6 & $\begin{array}{l}\mathrm{KSS}=85.7 \\
\mathrm{MSTS}=19.2 \\
\mathrm{WOMAC}=23.1\end{array}$ \\
\hline 2 & Vaishya et al. [6] & 10 & 48 & $\mathrm{KSS}=88$ \\
\hline 3 & Berend \& Lombardi [10] & 39 & 45 & $\mathrm{KSS}=87$ \\
\hline 4 & Rosen \& Strauss [12] & 24 & 11 & $\begin{array}{l}71 \% \text { patients were able to return } \\
\text { to pre-operative ambulation level }\end{array}$ \\
\hline 5 & Our study & 24 & 22.1 & $\begin{array}{l}\mathrm{KSS}=75.7 \\
\mathrm{MSTS}=19.3\end{array}$ \\
\hline
\end{tabular}

KSS, Knee Society Score; MSTS, Musculoskeletal Tumor Society; WOMAC, Western Ontario and McMaster Osteoarthritis Index score 
showed cement-associated hypotension (mean arterial pressure $(\mathrm{MAP})<70 \mathrm{mmHg}$, or reduction in MAP $>15 \mathrm{mmHg}$ ) in $38 \%$ of patients and oxygen desaturation in $25 \%$ of patients [18]. Data from three studies show the incidence of intraoperative mortality during cemented THR to be $0.11 \%(95 \%$ CI $0.07-0.15 \%)$ in elderly patients [19-21]. Careful monitoring by the anaesthetist is essential during cementing and during release of tourniquet $[21,22]$. Both the cases in our series recovered with prompt identification of the problem, resuscitation and intensive care management. Deep infection requiring debridement was seen in one case $(4.1 \%)$. Multiple surgeries, extensive exposure and associated co-morbidities increase the chances of infections in elderly patients. In our case - the patient who was a diabetic - the infection settled completely with debridement and antibiotics.

Use of endoprosthesis for DFN in elderly patients is not common. Our experience at our busy tertiary referral Level 1 trauma hospital where we manage nearly 300 nonunion cases annually gave us the opportunity to come across such cases on a regular basis and also retrospectively analyse 24 cases of DFN in elderly patients managed with cemented endoprosthesis in five years. This surgery can be technically demanding and best results are achieved when performed by experienced surgeons familiar to the procedure. Also, the presence of an experienced team of anaesthetists and intensivists is essential as good peri-operative and postoperative care is vital while managing these elderly patients with co-morbidities to achieve favourable outcomes.

Our relatively short follow-up, retrospective study design and single centre results are limitations of our study. However, our series of 24 elderly patients managed with megaprosthesis for DFN is the largest series and our detailed analysis of the outcomes show that it is a useful viable procedure in elderly patients.

\section{Conclusion}

Revision fixation in DFN in elderly patients is difficult due to poor bone stock, osteoporosis and medical co-morbidities. Cemented modular megaprosthesis is a useful single-stage option that permits immediate full weight-bearing, restores most patients to an acceptable functional status capable of doing all activities of daily living and gives favourable outcomes.

Funding information This study was funded by the Ganga Orthopaedic Research \& Education Foundation (GOREF).

\section{Compliance with ethical standards}

Conflict of interest The authors declare that they have no conflict of interest.
The study was performed in accordance with the ethical standards in the 1964 Declaration of Helsinki.

Abbreviations $D F N$, distal femoral nonunions; $L P S$, Limb Preservation System; ASA, American Society of Anaesthesiologists; $C P M$, continuous passive motion; KSS, Knee Society Score; MSTS, Musculoskeletal Tumor Society; $B C I S$, bone cement implantation syndrome; $M A P$, mean arterial pressure; $T H R$, total hip replacement

\section{References}

1. Ebraheim NA, Martin A, Sochacki KR, Liu J (2013) Nonunion of distal femoral fractures: a systematic review. Orthop Surg 5(1):4650. https://doi.org/10.1111/os.12017 Review

2. Kanakeshwar RB, Jayaramaraju D, Agraharam D, Rajasekaran S (2017) Management of resistant distal femur non-unions with allograft strut and autografts combined with osteosynthesis in a series of 22 patients. Injury 48(Suppl 2):S14-S17. https://doi.org/10. 1016/S0020-1383(17)30488-6

3. Chan DB, Jeffcoat DM, Lorich DG, Helfet DL (2009) Nonunions around the knee joint. Int Orthop 34(2):271-281

4. Moloney GB, Pan T, Van Eck CF, Patel D, Tarkin I (2016) Geriatric distal femur fracture: are we underestimating the rate of local and systemic complications? Injury 47(8):1732

5. Basu N, Natour M, Mounasamy V, Kates SL (2016) Geriatric hip fracture management: keys to providing a successful program. Eur J Trauma Emerg Surg 42(5):565-569 Review

6. Vaishya R, Singh AP, Hasija R, Singh AP (2011) Treatment of resistant nonunion of supracondylar fractures femur by megaprosthesis. Knee Surg Sports Traumatol Arthrosc 19(7): 1137-1140. https://doi.org/10.1007/s00167-011-1416-1

7. Tarantino U, Cerocchi I et al (2011) Bone healing and osteoporosis. Aging Clin Exp Res 23(2 Suppl):62-64 Review

8. Farmer RP et al (2014) Osteoporosis and the orthopaedic surgeon: basic concepts for successful co-management of patients' bone health. Int Orthop 38(8):1731-1738

9. Hart GP, Kneisl JS, Springer BD, Patt JC, Karunakar MA (2016) Open reduction vs distal femoral replacement arthroplasty for comminuted distal femur fractures in the patients 70 years and older. $\mathrm{J}$ Arthroplast 1:202-206

10. Berend KR, Lombardi AV (2008) Distal femoral replacement in nontumor cases with severe bone loss and instability. Clin Orthop Relat Res 2:485-492

11. Davila J, Malkani A, Paiso JM (2001) Supracondylar distal femoral nonunions treated with a megaprosthesis in elderly patients: a report of two cases. J Orthop Trauma 8:574-578

12. Rosen AL, Strauss E (2004) Primary total knee arthroplasty for complex distal femur fractures in elderly patients. Clin Orthop Relat Res 425:101-105

13. Kolmert L, Wulff K (1982) Epidemiology and treatment of distal femoral fractures in adults. Acta Orthop Scand 53(6):957-962

14. Court-Brown CM (2006) Caesar B (2006) epidemiology of adult fractures: a review. Injury. 37(8):691-697 Review

15. Bettin CC, Weinlein JC, Toy PC, Heck RK (2016) Distal femoral replacement for acute distal femoral fractures in elderly patients. $\mathrm{J}$ Orthop Trauma 9:503-509

16. Forster MC, Komarsamy B, Davison JN (2005) Distal femoral fractures: a review of fixation methods. Injury 2:97-9108

17. Lundh F, Sayed-Noor AS, Brosjö O, Bauer H (2014) Megaprosthetic reconstruction for periprosthetic or highly 
comminuted fractures of the hip and knee. Eur J Orthop Surg Traumatol 24:553. https://doi.org/10.1007/s00590-013-1237-7

18. Herrenbruck T, Erickson EW, Damron TA, Heiner J (2002) Adverse clinical events during cemented long-stem femoral arthroplasty. Clin Orthop Relat Res 395:154-163

19. Coventry MB, Beckenbaugh RD, Nolan DR, Ilstrup DM (1974) 2, 012 total hip arthroplasties. A study of postoperative course and early complications. J Bone Joint Surg Am 2:273-284

20. Ereth MH, Weber JG, Abel MD, Lennon RL, Lewallen DG, Ilstrup DM, Rehder K (1992) Cemented versus noncemented total hip arthroplasty-embolism, hemodynamics, and intrapulmonary shunting. Mayo Clin Proc 11:1066-1074
21. Parvizi J, Holiday AD, Ereth MH, Lewallen DG (1999) The Frank Stinchfield award. Sudden death during primary hip arthroplasty. Clin Orthop Relat Res 369:39-48

22. Donaldson AJ, Thomson HE, Harper NJ, Kenny NW (2009) Bone cement implantation syndrome. Br J Anaesth 102(1):12-22. https:// doi.org/10.1093/bja/aen328

Publisher's note Springer Nature remains neutral with regard to jurisdictional claims in published maps and institutional affiliations. 